\title{
Outcome of Open Abdominal Management Following Military Trauma
}

DOI:

10.1002/bjs.10813

\section{Document Version}

Accepted author manuscript

Link to publication record in Manchester Research Explorer

\section{Citation for published version (APA):}

Pengelly, S., Berry, J., Herrick, S., Bowley, D., \& Carlson, G. (2018). Outcome of Open Abdominal Management Following Military Trauma. British Journal of Surgery, 980-986. https://doi.org/10.1002/bjs.10813

\section{Published in:}

British Journal of Surgery

\section{Citing this paper}

Please note that where the full-text provided on Manchester Research Explorer is the Author Accepted Manuscript or Proof version this may differ from the final Published version. If citing, it is advised that you check and use the publisher's definitive version.

\section{General rights}

Copyright and moral rights for the publications made accessible in the Research Explorer are retained by the authors and/or other copyright owners and it is a condition of accessing publications that users recognise and abide by the legal requirements associated with these rights.

\section{Takedown policy}

If you believe that this document breaches copyright please refer to the University of Manchester's Takedown Procedures [http://man.ac.uk/04Y6Bo] or contact uml.scholarlycommunications@manchester.ac.uk providing relevant details, so we can investigate your claim.

\section{OPEN ACCESS}


BJS

\section{Outcome of Open Abdominal Management Following Military Trauma}

\begin{tabular}{|r|l|}
\hline Journal: & British Journal of Surgery \\
\hline Manuscript ID & BJS-1241-Aug-17.R2 \\
\hline Wiley - Manuscript type: & Original Article \\
\hline Date Submitted by the Author: & 20 -Nov-2017 \\
\hline Complete List of Authors: & $\begin{array}{l}\text { Pengelly, Steven; University of Manchester; Royal Centre for Defence } \\
\text { Medicine } \\
\text { Berry, James; University of Manchester; Royal Centre for Defence Medicine } \\
\text { Herrick, Sarah; University of Manchester } \\
\text { Bowley, Douglas; Royal Centre for Defence Medicine } \\
\text { Carlson, Gordon; University of Manchester; Salford Royal NHS Foundation } \\
\text { Trust, National Intestinal Failure Centre, Department of Surgery }\end{array}$ \\
\hline Keywords: & $\begin{array}{l}\text { Military personnel, Laparotomy, Postoperative complications, Open } \\
\text { abdomen, Retrospective Studies }\end{array}$ \\
\hline
\end{tabular}

\section{SCHOLARONE}

Manuscripts 


\title{
Outcome of Open Abdominal Management Following Military \\ Trauma
}

\author{
S Pengelly ${ }^{1,2}$, JEA Berry ${ }^{1,2}$, SE Herrick ${ }^{1}$, DM Bowley ${ }^{2}$, GL Carlson ${ }^{1,3}$ \\ 1 University of Manchester, UK \\ 2 Royal Centre for Defence Medicine, Birmingham, UK \\ 3 National Intestinal Failure Centre, Department of Surgery, Salford \\ Royal NHS Foundation Trust, UK
}

Corresponding Author: Steven Pengelly, steviep@doctors.org.uk.

29 Mount Stone Road, Plymouth, PL1 3RW. Tel: 07540840020

Funding: Surgeon General's Research Group, Defence Medical Services

Original Article

Not commissioned

Keywords: Military personnel, laparotomy, postoperative complications, open abdomen, retrospective studies 
55

56

57

58

59 


\begin{abstract}
Background

Temporary abdominal closure (TAC) is increasingly common after military and civilian major trauma. Primary fascial closure cannot be achieved after TAC in $30 \%$ of civilian patients; subsequent abdominal wall reconstruction carries significant morbidity. This retrospective review aims to determine this morbidity in a UK military cohort.
\end{abstract}

\title{
Methods
}

A prospectively maintained database of all injured personnel from the Iraq and Afghanistan conflicts was searched for all patients who had undergone laparotomy in a deployed military medical treatment facility. This database, the patients' hospital notes and their primary care records were searched.

\section{Results}

From June 2003 to August 2014, 150 patients underwent laparotomy, were repatriated to the UK and had records available for study. $77(51.3 \%)$ had fascial closure at first laparotomy; 73(48.7\%) had a period of TAC. Of the 73 with TAC, 2 died prior to closure; 2 had significant abdominal wall loss from blast injury and were excluded from analysis. 65/69(94.2\%) remaining TAC patients were able to undergo delayed primary fascial closure. The median duration of follow-up from injury was 1257 (range 1-4677) days. 9/73 (12.3\%) patients who underwent delayed primary closure subsequently developed an incisional hernia, compared to $10 / 77(13.0 \%)$ of those whose abdomens were closed at the primary laparotomy (Relative Risk 0.94, $p=1.000$ ). 


\section{Conclusion}

Rates of delayed primary closure of abdominal fascia after temporary abdominal closure appear high Subsequent rates of subsequent incisional hernia formation were similar in those undergoing delayed primary closure with those closed primarily. 


\section{Introduction}

The treatment of patients with severe abdominal injuries has been revolutionised by the concept of "damage control laparotomy" (DCL). As opposed to a "definitive laparotomy', involving a full laparotomy with definitive repair of all injuries, which might take several hours, DCL minimises the time initially spent in theatre and so reduces the impact of acute trauma coagulopathy and its consequences. In DCL, the patient undergoes a shortened initial laparotomy, typically limited to arrest of haemorrhage (with shunting or repair of major vascular injuries), control of hollow visceral injury by oversew or resection and stapled closure of bowel (leaving the closed ends in discontinuity) and application of temporary abdominal closure ${ }^{1}$.

DCL has been found to be associated with a substantial reduction in hospital mortality after major vascular and enteric trauma, when compared with a traditional definitive laparotomy ${ }^{2}$. One of the key limitations of DCL is the need to manage the open abdomen after the initial procedure. A variety of techniques for temporary abdominal closure (TAC) have been developed to support the management of the patient during this period, pending definitive surgery to close the abdominal fascia, including the 'vacuum pack'3, the 'Wittmann patch'4, 'Bogota Bag', mesh/sheet closure $^{6}$, dynamic retention sutures ${ }^{7}$ and mesh-mediated fascial traction ${ }^{8}$. Alternatively, the abdomen may be left open to heal by secondary intention, leading to a 'planned ventral hernia', repair of which can be undertaken subsequently'.

While the abdomen may be closed conventionally (primary fascial closure, PFC) in those patients who have stabilised rapidly, the proportion of patients who undergo PFC after a period of management with an open abdomen appears to vary considerably, depending on the initial indication for surgery. Intra-abdominal sepsis 
is the commonest indicator for open abdominal management in civilian practice in the $\mathrm{UK}^{10}$ and was associated with PFC in fewer than half of the 233 patients studied in one review ${ }^{11}$. In contrast, much higher rates of PFC (almost $70 \%$ ) have been reported after DCL for trauma, which remains the most common indication for this treatment in the United States ${ }^{11}$.

Approximately $10 \%$ of wounds sustained on military operations are to the abdomen $^{12}$. If, as indicated above, almost $30 \%$ of military patients managed with an open abdomen are not suitable for PFC, it was hypothesised that a significant number of servicemen with abdominal injuries would require later abdominal wall reconstruction. The extent of these problems, the resulting morbidity and mortality and resource implications for British military (and civilian) surgery are currently unclear. The aim of the present study was therefore to study the management of the abdominal wall following injury in the recent conflicts in Iraq and Afghanistan, to determine the rates of PFC and need for subsequent abdominal wall reconstruction in patients treated after a period of open abdominal management and to assess the resulting morbidity and mortality. The current study reports outcome in accordance with the PROCESS guidelines for case series ${ }^{13}$. 


\section{Methods}

\section{Sources of Data}

The Joint Theatre Trauma Registry (JTTR) is an electronic database established to aid service improvement in the treatment of military casualties. It has an entry for all deployed trauma cases (initially only those requiring trauma team activation, but then expanded to include all trauma patients repatriated to the Royal Centre for Defence Medicine (RCDM) since the start of the second Gulf conflict in 2003). Data are collected prospectively in the field hospital, as each major trauma occurs, by the deployed Trauma Nurse Co-ordinator, one of whom is on-call for data collection 24 hours a day. Data quality is therefore dependent on the training of these individuals, along with the training of the scribe for each individual major trauma ${ }^{14,15}$. Data on patients transferred to RCDM were obtained from direct access to the RCDM clinical records. The Defence Medical Information Capability Project (DMICP) is the primary care records system for the UK Armed Forces. Records for current and ex-serving personnel can be accessed remotely from any DMICP terminal. The records of all patients who had undergone a laparotomy in a deployed medical treatment facility were additionally searched, to determine whether the patients identified from review of the JTTR subsequently required treatment for complications of their trauma laparotomy in hospitals other than RCDM or in primary care.

\section{Data collected}

The JTTR was searched for all patients who had sustained an abdominal injury on military operations between $1^{\text {st }}$ January 2003 and $31^{\text {st }}$ December 2013. The JTTR entries for these patients were reviewed to exclude patients that had not been repatriated to RCDM, and those with abdominal injuries so minor that they did not require a laparotomy. The remaining patients all had their mechanism of injury, injury 
severity score $(\mathrm{ISS})^{16}$, and penetrating abdominal injury index (PATI) ${ }^{17}$ score calculated, as well as volume and type of resuscitation fluid used. After the patient was loaded onto the aeromedical evacuation flight and arrived in RCDM, fluid resuscitation data became less reliable as notes became split between multiple records. For this reason, fluid resuscitation data for all patients were only analysed for the first 24 hours after injury as. Medical notes were also reviewed at RCDM to determine indication for laparotomy, operative findings, the technique used for closing the abdominal wall and any subsequent abdominal reconstruction required, the length of hospital and ITU stay. RCDM notes and primary care records were reviewed to determine long-term complications including, mortality, intestinal fistulation, hernia and record of subsequent hospital admissions with intestinal obstruction. Primary care records were available up until the patient left the Armed Forces, which was defined as the end of follow-up. All entries for all planned and unplanned care were reviewed for all patients during this period, specifically noting a clinical diagnosis (and treatment) of hernia, intestinal fistula, and intestinal obstruction.

The data recorded in the JTTR were confirmed by examination of the medical records. Abdominal closure at the initial laparotomy was defined as 'Early Primary Closure' $(E P C)^{18}$. Injuries were classified according to cause as either from gunshot wound (GSW); penetration from weapons such as grenades and mortar; or nearby blast from weapons such as improvised explosive devices (IEDs), with and without abdominal penetration. 


\section{Ethical permission}

This study was registered with RCDM (RCDM/Res/Audit/1036/14/0432), and University Hospitals Birmingham (CARMS-11957). No patient identifiable data were recorded.

\section{Statistical Analysis}

Non-parametric data were expressed as median (range). Comparisons between groups were undertaken using the Mann-Whitney $U$ test. Categorical data were analysed using Fisher's exact test and Chi-squared tests. Survival curves were constructed, then compared using the log-rank test. Statistical significance was defined as a $p<0.05$. Data were analysed using GraphPad Prism 7 (Graphpad Software Ltd., San Diego Ca. USA). 


\section{Results}

Some 612 patients were found on JTTR to have had abdominal injuries of some kind. Patients who did not return to RCDM either because they died, were discharged or returned to duties because they only had minor injuries, were excluded. 241 sets of case notes were then reviewed (Figure 2.1). Laparotomy was undertaken in a total of 155 patients who survived to be repatriated to RCDM. Laparotomy was undertaken to achieve proximal vascular control or to defunction the bowel for severe open pelvic injury in 24 patients (Table 2.1).

Abdominal injury was identified following initial assessment in 143 patients. Ten patients $(7.0 \%)$ were treated conservatively, with a median (range) ISS of 18.5 (529). Seven of these patients had a non-penetrating injury and three a penetrating injury. It was not possible to determine whether or not a laparotomy had been performed in two patients (1.4\%), due to missing casenotes. The remaining 131 patients $(91.6 \%)$ underwent laparotomy for suspected intra-abdominal injury. No intra-abdominal pathology was found at laparotomy in 11 (8.4\%) of these.

Of the 155 patients who underwent laparotomy, 77 (49.7\%) underwent abdominal closure at the initial procedure (early primary closure-EPC), whereas temporary abdominal closure (TAC) was utilised in 73 patients (47.1\%). In five patients $(3.2 \%)$ it was unclear which method of abdominal closure had been used, or the notes were unobtainable and these patients were therefore excluded from further analysis. Of the 73 patients undergoing TAC, 66 were managed with a vacuum pack, 2 with a Bogota bag, and in 5 patients the method was not recorded (Table 2.2). All patients were male.. Overall survival rates were similar between the two groups (Figure 2.2) . 
Of the 73 patients who had TAC, two patients died prior to abdominal closure and two had significant abdominal wall loss from blast injury and were therefore not suitable for primary closure. Delayed primary closure (DPC) was undertaken in 65 of the 69 patients in whom it was possible, giving a primary fascial closure rate of $94.2 \%(65 / 69)$, after a median of 2 procedures (range $2-7$ ), at a median of 2 days after the first laparotomy (range 2-8). Of the remaining four patients, one was managed with an anterior thigh flap, and the other three were managed with separation of components with reinforcement by prosthetic material. The four patients who were unable to undergo DPC did not have any statistically significant differences in their age (29.5 years $\vee 24$ years, $p=0.167)$, ISS ( $29 \vee 32, p=0.660)$, volume of crystalloid in first 24 hours ( 1.75 litres $v 2$ litres, $p=1.000$ ) or volume of red cells in first 24 hours ( 15 units $v 17$ units, $p=0.771$ ) when compared to the 65 patients who underwent DPC.

\section{Complications}

Primary care records were obtainable for all but nine of the 155 patients $(94.2 \%)$. Median duration of follow-up from injury was 1257 (range 1-4677) days. For all laparotomy patients there was a significant incidence of re-attendance to medical services with hernia formation (12.9\%), intestinal obstruction (4.5\%) and a requirement for unplanned laparotomy $(7.1 \%)$, but the rates of these complications did not differ significantly between patients who underwent primary fascial closure and those who had undergone TAC (table 2.3). The median time to presentation with hernia was 803 (range 15-1610) days for TAC patients, and 1175 (507-1589) days for EPC patients; $(p=0.345)$. Unplanned relaparotomies were undertaken for bleeding $(n=2)$, stoma problems $(n=2)$, rectus muscle necrosis $(n=2)$, intra-abdominal 
sepsis $(n=2)$, anastomotic leak $(n=1)$, small bowel obstruction $(n=1)$ and, in one case, to create a colostomy $(n=1)$.

TAC patients with an isolated penetrating abdominal injury stayed on the ITU for a median (range) 9 (2-49) days, and in hospital for 31 (6-124) days, and had a median (range) ISS of 20.5 (5-57). This was significantly longer than EPC patients who stayed on ITU for $2(0-20)$ days $(p<0.001)$, and in hospital for $15(6-68)$ days $(p<0.001)$. These patients had a median (range) ISS of $10.5(1-41), p=0.003$. 


\section{Discussion}

This data confirm that military patients requiring trauma laparotomy during recent UK combat experience are an extremely severely injured cohort, with a median ISS of 26 and a requirement for transfusion of median 8 units of RBCs in the first 24 hours after injury. This study also confirms that Damage Control Surgery has been widely adopted by UK military surgeons with $47 \%$ of servicemen injured between $1^{\text {st }}$ January 2003 and $31^{\text {st }}$ December 2013 having TAC used at primary laparotomy in military MTFs. The TAC cohort were much more severely injured than the EPC cohort, but had a similar 30 -day mortality $(2.7 \%$ vs. $1.3 \%)$.

Primary fascial closure was achieved in nearly all TAC patients after a median of 2 procedures (range 2-7). Complication rates were modest and did not differ significantly between TAC and PFC patients. An overall incisional hernia rate of $12.9 \%$ is similar to the $12.8 \%$ rate reported in a meta-analysis of emergency and elective laparotomies ${ }^{19}$ and rates of small bowel obstruction of $4.5 \%$ compare favourably to approximately $9 \%$ reported previously following laparotomy in civilian practice $^{20}$. Unplanned re-laparotomy was required in 9\% of EPC patients but only 4\% of TAC patients, suggesting that the DCL may have been under-used in some patients who would have benefitted from the damage control techniques including abdominal packing. Follow-up has been good in this military cohort and an incisional hernia was identified in $13.0 \%$ of EPC patients and $12.3 \%$ of TAC patients. The specific details of the methods used for laparotomy wound closure were not available and might conceivably have affected the rate of incisional hernia development. However, it seems unlikely that this would have introduced a systematic bias into the outcome of abdominal closure, as there is no reason to suspect that closure techniques would not have been evenly distributed among patient cohorts. 
The results of the present study provided no evidence to support the hypothesis that the increasing use of TAC would result in significant numbers of UK servicemen requiring early abdominal wall reconstruction. The rate of direct primary closure following TAC, at $94.2 \%$, compares favourably to other published series. This may partly be due to of the youth and fitness of this cohort. The largest series to have previously examined this issue reported on the outcome of 572 patients with a mean age of 39 years, and with $20 \%$ of their patients being over 55 years ${ }^{21}$, compared to the median age of 25 years in this cohort, with no patients over 55 years. This previous study noted a DPC rate of only $59 \%$. Although these patients were older than those reported here, they were less severely injured, with an ISS of 29.6, compared to 32 in the current study. Other than age, no explanation for this difference in closure rates is apparent. One American study of civilian trauma achieved a $100 \%$ closure rate in a subset of 29 patients using a sequential closure protocol, although the authors did not discuss why other patients in their series did not follow the same protocol ${ }^{22}$.

There have been few studies which have addressed the outcome of management of the open abdomen after penetrating trauma, and almost nothing is known about longer term outcome in a group of patients who increasingly survive their injuries, and who may therefore present clinical challenges for both military and civilian surgical practice.

A Scandinavian study followed up 55 TAC patients for 5 years with interviews and a physical examination, and found a cumulative hernia rate of $61 \%$ over this time ${ }^{23}$. The percentage of trauma patients in this group of 55 was not provided and this group of patients was taken from a larger cohort of 155 described in an earlier study, of whom only $6 \%$ were trauma patients ${ }^{8}$. While a prospective study with a carefully 
planned protocol of regular telephone, clinic and even cross sectional radiology follow up would, have been more scientifically robust and very likely have identified more hernias, this would not have been practical in such a large study of patients with varying follow up and clinical need. The hernia rate reported in the present study is likely to be an underestimate because of ascertainment bias - patients with a hernia who did not present for diagnosis or treatment because of symptoms would likely have been overlooked. A detailed, long term prospective study over at least a decade would have been required to address this formally. However, these data are similar to those reported by Howdieshell and colleagues, who followed 88 TAC patients who had undergone TAC for a mean of four years ${ }^{24}$ and found that 16.7 had developed a hernia and in addition, it is unclear whether hernias so small or asymptomatic that they do not cause the patient to present to a doctor, are significant with regard to service provision.

The only previously published British series studying patients who had undergone open abdominal management for trauma was carried out at the UK field Hospital, Camp Bastion ${ }^{25}$. In that study, 47 out of 55 surviving patients (85\%) who had undergone TAC were able to undergo DPC. This is slightly lower, but roughly comparable to the figure of $94.2 \%$ reported in the present study and the significance of the difference is unclear. It may, however be due to the inclusion of a number of Afghan nationals in that series, for whom evacuation and subsequent reconstructive surgery was not feasible. Confounding factors that influence the management decisions around treating local nationals (such as requirement to transfer into the host nation medical system) are beyond the scope of this paper.

In line with the changes in the UK Armed Forces to align with the recommendations of the National Security Strategy and Strategic Defence and Security Review, it is 
most unlikely that a military patient cohort of this size will be seen again in the foreseeable future. Although follow-up of a military cohort is likely to be easier than long-term follow-up of civilian patients after treatment of traumatic injury ${ }^{26}$, primary care data were only available up to the point of the patient leaving the military. If a patient had left the military because of abdominal problems, either as a medical discharge or self-initiated discharge because they no longer felt able to perform their duties, late complications including hernia development or bowel obstruction in the present patient cohort would not have been identified. Combined military and civilian primary care data for all patients up to a fixed time point after injury would more accurately portray differences between TAC and non-TAC patients.

TAC and EPC patients were of a similar age and had similar mechanisms of injury; patients who underwent TAC were significantly more injured and were given significantly more red cells in the first 24 hours after injury. This was also true for patients who only had penetrating abdominal injury (ISS 20.5 in TAC patients; 10.5 in EPC patients). This means outcome differences, such as the significantly increased ITU and hospital stays observed between the two groups is almost certainly due to increased injury severity, rather than the use of TAC per se. It seems unlikely that a randomised control trial of TAC in abdominal trauma patients versus definitive laparotomy would now be possible due to lack of equipoise, or indeed considered ethical and future research is more likely to focus instead on techniques of haemostasis and TAC.

No evidence was found that the number of laparotomies, or amount of crystalloid or red cell transfusion was associated with an inability to undergo primary fascial closure. Additional accurate transfusion data up to the point of the second laparotomy might have elucidated this more clearly, but after leaving the deployed 
hospital on the aeromedical evacuation flight there was poor concordance between the JTTR data and the medical notes, which were spread also between different folders and so may have had sections missing. This later infusion data could therefore not be relied upon.

Because of the small number of patients who underwent an abdominal wall reconstructive procedure, it is not possible to draw any conclusions regarding the optimum implant material or technique. Only four patients who had undergone TAC, and did not have significant abdominal wall loss or die prior to closure, were unable to undergo primary fascial closure. The small size of this group makes finding any cause or association for this non-closure difficult.

The adoption of damage control surgery has resulted in exceptionally high rates of survival for critically-injured patients after laparotomy for combat injury. The logistic requirements to treat this cohort of patients (particularly transfusion support) are, however, high. Early post-operative complications rates are acceptable; and rates of abdominal complications are not significantly higher than those seen in less severely injured patients undergoing primary closure. In this series of combat laparotomies in British servicemen, $94.2 \%$ of patients underwent DPC after a range of 2 to 7 relaparotomies. TAC is associated with relatively low rates of subsequent incisional hernia formation; but, approximately 1 in 8 patients have been found to develop incisional hernias and this suggests that more research is needed to determine optimal methods of fascial closure. Furthermore, some military patients will require more complex forms of abdominal wall reconstruction, particularly when abdominal wall loss occurred as a direct result of injury. Further study is required in this patient population to assess determine the optimum techniques for reconstruction. 


\section{References}

1. Stone HH, Strom PR, Mullins RJ. Management of the major coagulopathy with onset during laparotomy. Ann Surg. 1983 May;197(5):532-5.

2. Rotondo MF, Schwab CW, McGonigal MD, Phillips GR, Fruchterman TM, Kauder DR, et al. "Damage control": an approach for improved survival in exsanguinating penetrating abdominal injury. J Trauma. 1993 Sep;35(3):37582-3.

3. Barker DE, Kaufman HJ, Smith LA, Ciraulo DL, Richart CL, Burns RP. Vacuum pack technique of temporary abdominal closure: a 7-year experience with 112 patients. J Trauma. 2000 Feb;48(2):201-6-7.

4. Wittmann DH, Aprahamian C, Bergstein JM. Etappenlavage: Advanced diffuse peritonitis managed by planned multiple laparotomies utilizing zippers, slide fastener, and Velcro?? analogue for temporary abdominal closure. World J Surg. 1990;14(2):218-26.

5. Borráez O. Manejo del Abdomen Séptico. Utilización del Polivinilo. In: XV Congreso “Avances en Cirugía e Infección.” Bogotá; 1989.

6. Ciresi DL, Cali RF, Senagore AJ. Abdominal closure using nonabsorbable mesh after massive resuscitation prevents abdominal compartment syndrome and gastrointestinal fistula. Am Surg. 1999 Aug;65(8):720-4.

7. Urbaniak RM, Khuthaila DK, Khalil AJ, Hammond DC. Closure of Massive Abdominal Wall Defects. Ann Plast Surg. 2006 Nov;57(5):573-7.

8. Acosta S, Bjarnason T, Petersson U, Pålsson B, Wanhainen A, Svensson M, et al. Multicentre prospective study of fascial closure rate after open abdomen with vacuum and mesh-mediated fascial traction. Br J Surg. 2011;98(5):73543.

9. Fabian TC, Croce MA, Pritchard FE, Minard G, Hickerson WL, Howell RL, et al. Planned ventral hernia. Staged management for acute abdominal wall defects. Ann Surg. 1994 Jun;219(6):643-50.

10. Carlson G, Patrick H, Amin Al, McPherson G, MacLennan G, Afolabi E, et al. Management of the open abdomen: a national study of clinical outcome and safety of negative pressure wound therapy. Ann Surg. 2013 Jun;257(6):11549.

11. Quyn AJ, Johnston C, Hall D, Chambers A, Arapova N, Ogston S, et al. The open abdomen and temporary abdominal closure systems--historical evolution and systematic review. Colorectal Dis. 2012 Aug;14(8):e429-38.

12. Belmont PJ, McCriskin BJ, Sieg RN, Burks R, Schoenfeld AJ. Combat wounds in Iraq and Afghanistan from 2005 to 2009. J Trauma Acute Care Surg. 2012;73(1):3-12.

13. Agha RA, Fowler AJ, Rajmohan S, Barai I, Orgill DP. Preferred reporting of case series in surgery; the PROCESS guidelines. Int J Surg. 2016;36:319-23.

14. Smith J, Hodgetts T, Mahoney P, Russell R, Mcleod J. Trauma Governance in the UK Defence Medical Services. J R Army Med Corps. 2007;153(4):239-42. 
15. Smith I, Naumann D, Guyver P, Bishop J, Davies S, Lundy J, et al. Interobserver Variability in Injury Severity Scoring After Combat Trauma: Different Perspectives, Different Values? J Spec Oper Med. 2015;15(2):86-93.

16. Baker SP, O'Neill B, Haddon W, Long WB. The injury severity score: a method for describing patients with multiple injuries and evaluating emergency care. $J$ Trauma. 1974;14(3):187-96.

17. Moore E, Dunn E, Moore J, Thompson J. Penetrating abdominal trauma index. J Trauma. 1981 Jun;21(6):439-45.

18. Sharrock AE, Barker T, Yuen HM, Rickard R, Tai N. Management and closure of the open abdomen after damage control laparotomy for trauma. A systematic review and meta-analysis. Injury. 2015;47(2):296-306.

19. Bosanquet DC, Ansell J, Abdelrahman T, Cornish J, Harries R, Stimpson A, et al. Systematic review and meta-regression of factors affecting midline Incisional hernia rates: Analysis of 14618 Patients. PLoS One. 2015;10(9):118.

20. ten Broek RPG, Issa Y, van Santbrink EJP, Bouvy ND, Kruitwagen RFPM, Jeekel J, et al. Burden of adhesions in abdominal and pelvic surgery: systematic review and met-analysis. BMJ. 2013;347:f5588.

21. Dubose JJ, Scalea TM, Holcomb JB, Shrestha B, Okoye O, Inaba K, et al. Open abdominal management after damage-control laparotomy for trauma: a prospective observational American Association for the Surgery of Trauma multicenter study. J Trauma Acute Care Surg. 2013;74(1):113-20.

22. Burlew C, Moore E, Biffl W, Bensard D, Johnson J, Barnett C. One hundred percent fascial approximation can be achieved in the postinjury open abdomen with a sequential closure protocol. J Trauma Acute Care Surg. 2012;72(1):235-41.

23. Petersson U, Bjarnason T, Bjorck M, Montgomery A, Rogmark P, Svensson M, et al. Quality of life and hernia development 5 years after open abdomen treatment with vacuum-assisted wound closure and mesh-mediated fascial traction. Hernia. 2016;20(5):755-64.

24. Howdieshell TR, Proctor CD, Sternberg E, Cue JI, Mondy JS, Hawkins ML. Temporary abdominal closure followed by definitive abdominal wall reconstruction of the open abdomen. Am J Surg. 2004;188(3):301-6.

25. Smith IM, Beech ZKM, Lundy JB, Bowley DM. A Prospective Observational Study of Abdominal Injury Management in Contemporary Military Operations. Ann Surg. 2015;261(4):765-73.

26. Leukhardt WH, Golob JF, McCoy AM, Fadlalla AMA, Malangoni MA, Claridge JA. Follow-up disparities after trauma: a real problem for outcomes research. Am J Surg. 2010;199(3):348-53. 


\section{Acknowledgements}

The Academic Department of Military Emergency Medicine and Defence Analytical Services and Advice are thanked for collecting, collating and identifying the appropriate data for this paper. Because of the sensitive nature of the data collected for this study, requests to access the dataset from qualified researchers trained in human subject confidentiality protocols may be sent to the Academic Department of Military Surgery at RCDM, Birmingham. No preregistration exists for the studies reported in this article. 


\section{Tables}

Table 2.1: Indication for laparotomy in 155 patients

\begin{tabular}{|l|l|l|}
\hline Indication & $\begin{array}{l}\text { Number of } \\
\text { patients (\%) }\end{array}$ & $\begin{array}{l}\text { Median (range) } \\
\text { ISS }\end{array}$ \\
\hline $\begin{array}{l}\text { Suspected abdominal injury, confirmed } \\
\text { at laparotomy }\end{array}$ & $120(77.4 \%)$ & $26(1-75)$ \\
\hline $\begin{array}{l}\text { Suspected abdominal injury, negative } \\
\text { laparotomy }\end{array}$ & $11(8.4 \%)$ & $24(1-42)$ \\
\hline Proximal vascular control only & $11(8.4 \%)$ & $29(14-75)$ \\
\hline Intestinal defunctioning only & $9(5.8 \%)$ & $30(5-50)$ \\
\hline Proximal control and defunctioning & $3(1.9 \%)$ & $24(20-42)$ \\
\hline Notes missing & $1(0.6 \%)$ & 75 \\
\hline
\end{tabular}


Table 2.2: Demographics of laparotomy patients. Data are expressed are median (range). ${ }^{\dagger} 5$ sets of notes were unobtainable to determine whether patient was TAC/EPC

\begin{tabular}{|c|c|c|c|c|}
\hline Demographic & $\begin{array}{l}\text { All } \\
\text { laparotomy } \\
\text { patients } \\
(n=155)\end{array}$ & $\begin{array}{l}\text { TAC Patients } \\
(n=73)\end{array}$ & $\begin{array}{l}\text { EPC Patients } \\
(n=77)\end{array}$ & $p$ \\
\hline Age & $25(18-46)$ & $24(18-41)$ & $25(18-46)$ & 0.756 \\
\hline Mechanism of injury: & & & & 0.822 \\
\hline GSW & $39^{\dagger}$ & 18 & 20 & \\
\hline $\begin{array}{l}\text { Fragmentation and } \\
\text { penetrating blast }\end{array}$ & $48^{+}$ & 21 & 24 & \\
\hline $\begin{array}{l}\text { Blast(non- } \\
\text { penetrating) }\end{array}$ & $62^{+}$ & 31 & 29 & \\
\hline Blunt & 6 & 1 & 5 & \\
\hline ISS & $26(1-75)$ & $32(5-75)$ & $21(1-75)$ & $<0.001$ \\
\hline RBCs in first 24 hours & $0(0-76)$ & $17(0-76)$ & $2(0-49)$ & $<0.001$ \\
\hline
\end{tabular}




\begin{tabular}{|c|c|c|c|c|c|c|c|c|}
\hline Quintile & Patients & Dates & $\begin{array}{l}\text { TAC } \\
\text { patients }\end{array}$ & $\begin{array}{l}E P C \\
\text { patients }\end{array}$ & $\begin{array}{l}\text { Notes } \\
\text { unavailable }\end{array}$ & \% TAG & AledianISS & $\begin{array}{l}\text { Aledian } \\
\text { PATI }\end{array}$ \\
\hline $1^{\text {st }}$ & 31 & $24 / 6 / 3-8 / 9 / 7$ & 4 & 27 & $\theta$ & 12.9 & 17 & 13. \\
\hline$z^{\text {nd }}$ & 31 & to $13 / 8 / 9$ & 14 & 13 & 4 & 45.2 & 29 & 14.5 \\
\hline $3^{\text {rd }}$ & 31 & to $30 / 5 / 10$ & 14 & 16 & 1 & 45.2 & 33 & 8.5 \\
\hline $4^{\text {th }}$ & 31 & to $16 / 3 / 11$ & 20 & 11 & $\theta$ & 64.5 & 29 & 14.5 \\
\hline $5^{\text {th }}$ & 31 & to 5/9/14 & 20 & 11 & $\theta$ & 64.5 & 29 & 14.5 \\
\hline
\end{tabular}

Formatted: Normal

Formatted: Left, Space After: $0 \mathrm{pt}$, Line spacing: single

Formatted: Left, Indent: Left: 0", First line: 0", Space After: $0 \mathrm{pt}$, Line spacing: single

Formatted: Left, Space After: 0 pt, Line spacing: single

Formatted: Left, Space After: $0 \mathrm{pt}$, Line spacing: single

Formatted: Left, Space After: 0 pt, Line spacing: single

Formatted: Left, Space After: $0 \mathrm{pt}$, Line spacing: single

Formatted: Left, Space After: 0 pt, Line spacing: single

Formatted: Left, Space After: 0 pt, Line spacing: single

Formatted: Normal 
Table 2.4: Characteristics of patients who were able and unable to undergo primary fascial closure. All data are expressed are median (range).

\begin{tabular}{|l|l|l|l|l|}
\hline Demographic & $\begin{array}{l}\text { TAC patients } \\
(\mathrm{n}-69)\end{array}$ & $\begin{array}{l}\text { DPC } \\
(\mathrm{n}-65)\end{array}$ & $\begin{array}{l}\text { NPC } \\
(\mathrm{n}-4)\end{array}$ & \\
\hline Age & $24(18-41)$ & $24(18-38)$ & $29.5(23-41)$ & 0.167 \\
\hline ISS & $32(5-75)$ & $32(5-75)$ & $29(13-41)$ & 0.660 \\
\hline $\begin{array}{l}\text { Erystalloid (litres) in } \\
\text { first 24hrs }\end{array}$ & zlitres (0-12) & zlitres (0-12) & 1.75 litres (0-5.5) & 1.000 \\
\hline RBCs first 24hrs & 17 units (0-76) & 17 units (0-68) & 15 units (0-40) & 0.771 \\
\hline
\end{tabular}

TAC: temporary abdominal closure

DPC: delayed primary closure

NPC: not primarily-closed 
| Table 2.53- Primary and secondary care complications of TAC and EPC patients. ${ }^{\dagger} 5$ sets of notes were unobtainable to determine TAC/EPC status

\begin{tabular}{|l|l|l|l|l|}
\hline Complication & $\begin{array}{l}\text { All laparotomy } \\
\text { patients }(n=155)\end{array}$ & $\begin{array}{l}\text { TAC Patients } \\
\left(n=73^{+}\right)\end{array}$ & $\begin{array}{l}\text { EPC Patients } \\
\left(n=77^{+}\right)\end{array}$ & $p$ \\
\hline $\begin{array}{l}\text { Unplanned } \\
\text { relaparotomy }\end{array}$ & $11(7.1 \%)$ & $4(5.5 \%)$ & $7(9.1 \%)$ & 0.538 \\
\hline Hernia & $20(12.9 \%)$ & $9(12.3 \%)$ & $10(13.0 \%)$ & 1.000 \\
\hline Bowel obstruction & $7(4.5 \%)$ & $6(8.2 \%)$ & $1(1.3 \%)$ & 0.057 \\
\hline Fistula formation & $1(0.6 \%)$ & $1(1.4 \%)$ & 0 & 0.487 \\
\hline Death before 30 days & $3(1.9 \%)$ & $2(2.7 \%)$ & $1(1.3 \%)$ & 0.613 \\
\hline
\end{tabular}

TAC: temporary abdominal closure

EPC: early primary closure 
Table 2.6-Lengths of stay in patients with isolated penetrating abdominal injury. All data are expressed as median (range). +2 sets of notes unavailable to determine TAC/EPC status

\begin{tabular}{|l|l|l|l|l|}
\hline & All $(n-64) \pm$ & $\begin{array}{l}\text { FAC patients } \\
(n-28)\end{array}$ & $\begin{array}{l}\text { EPC patients } \\
(n-34)\end{array}$ & $P$ \\
\hline ISS & $17(1-57)$ & $20.5(5-57)$ & $10.5(1-41)$ & 0.003 \\
\hline Time on ITU & $5(0-49)$ & $9(2-49)$ & $2(0-20)$ & $<0.001$ \\
\hline Hospital stay & $21(6-124)$ & $31(6-124)$ & $15(6-68)$ & $<0.001$ \\
\hline
\end{tabular}




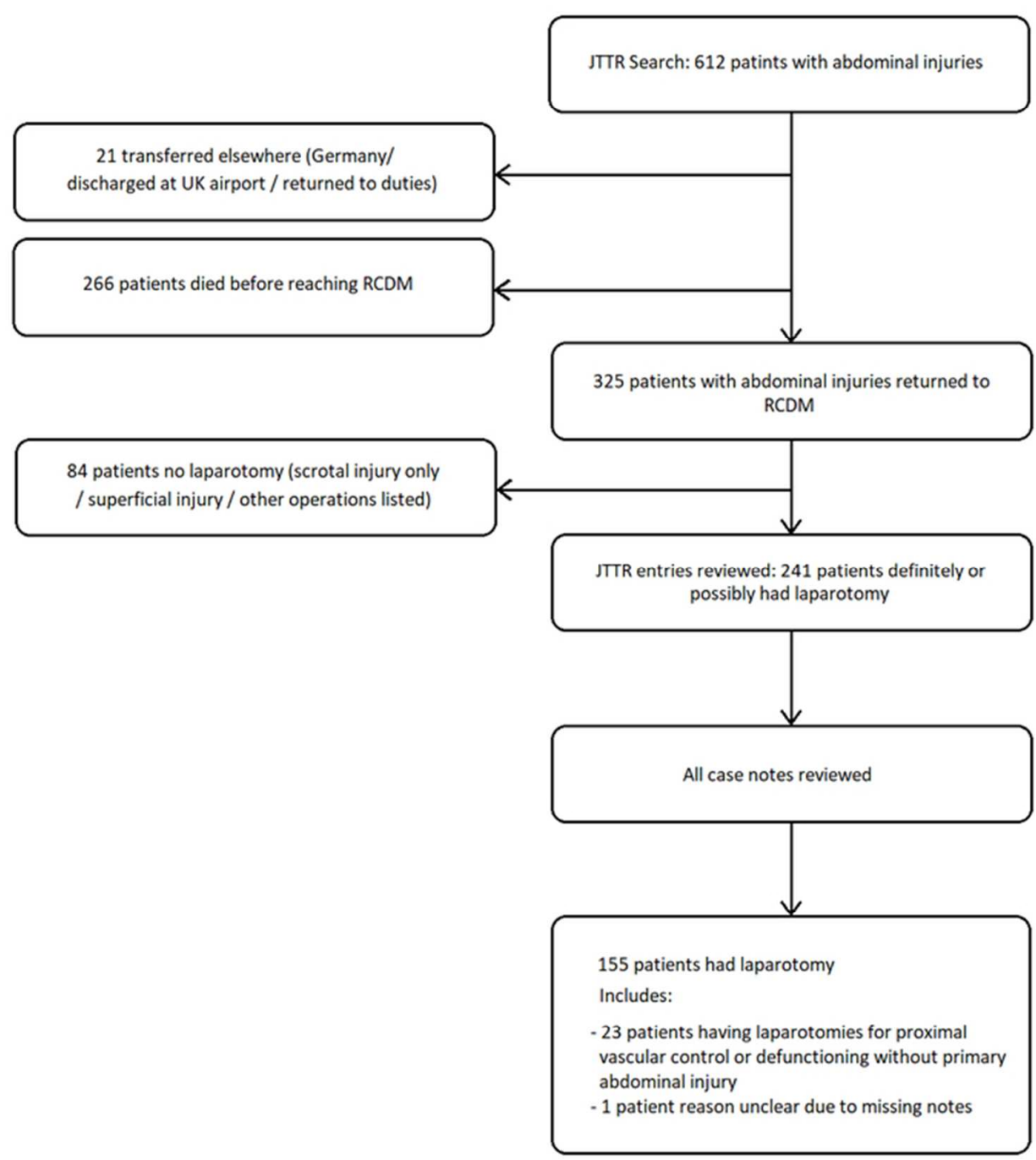

Figure 2.1: Outcome of JTRR search for $1^{\text {st }}$ Jan 2003 to $31^{\text {st }}$ Dec 2013

Figure 2.1: Outcome of JTTR search for 1st Jan 2003 to 31st Dec 2013 $30 \times 34 \mathrm{~mm}(600 \times 600 \mathrm{DPI})$ 


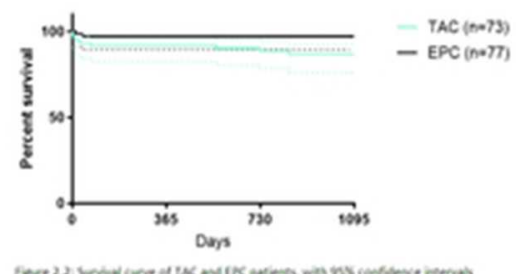

Figure 2.2: Survival curve of TAC and EPC patients, with 95\% confidence intervals

$8 \times 4 \mathrm{~mm}(600 \times 600 \mathrm{DPI})$

18

19

20

21

22

23

24

25

26

27

28

29

30

31

32

33

34

35

36

37

38

39

40

41

42

43

44

45

46

47

48

49

50

51

52

53

54

55

56

57

58

59

60

http://mc.manuscriptcentral.com/bjs 